ACTAS DEL

V CONGRESO

DE LA

ASOCIACIÓN

INTERNACIONAL

SIGLO DE ORO

Münster 1999

Editadas por

Christoph Strosetzki 


\title{
Agudeza emblemática en H. Domínguez Camargo: el bestiario en el Poema heroico a San Ignacio de Loyola
}

\author{
Carmen Pinillos
}

Los emblemas y conceptos son frutas del mismo árbol ${ }^{1}$

Conniemte lhabioitual de toda la literatura áurea es la presencia de elementos de diferente calliddad emablemática, en todos los géneros literarios y en todos los escritores de la öpoca: Cerwantes ${ }^{2}$, Tirso ${ }^{3}$, Calderón ${ }^{4}$... En la obra poética del novogranatense Hernando Domnonguez Camargo es un elemento fundamental de su sistema expresivo, en particular exall Poestua heroico a San Ignacio ${ }^{5}$. En el Poema heroico, la técnica de integración de Da matínerita ermblemática es la agudeza de ingenio, un mecanismo perfectamente calculaAld que responde a las categorías que comenta Gracián en su Agudeza y arte de ingenio ${ }^{6}$.

La aniisma afición de origen humanístico peninsular a los emblemas, empresas y jeregollifficos , .. se reproduce evidentemente en la colonia, como indica a propósito del Pentio vimeinal Alicia de Colombí-Monguió ${ }^{7}$. En el caso del Domínguez Camargo esta affición, sin duda, fue creada y fomentada por la Compañía de Jesús, a la que pertenecía. No podemos olvidar que en el siglo XVII, los jesuitas hacen suyo el género emblemáti100 y culltizan casi todos los tipos de libros de emblemas. Como señala Pedro Campa,

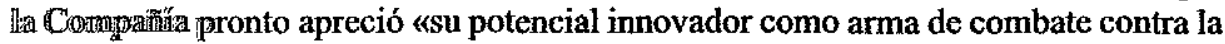
laerejulp protestante, como tex to de estudio, como vehículo para enaltecer a Dios, como formatio para su sistema de oración, y finalmente como medio para dar a conocer la

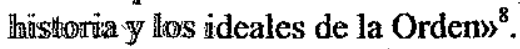

Así ell Poema heroico, exaltación del fundador de la Orden, resulta una obra sorprendente en cuanto a la abundancia y acumulación de referencias de origen emblemáti-

1 Praz, $1964,14$.

2 Anellati, l(997, 1998 y 1999; Cull, 1992a; Iffland, 1998; Pinillos, 1997.

3 Sminith, 1985.

4 Anellano, 1990; Cull, $1992 \mathrm{~b}$.

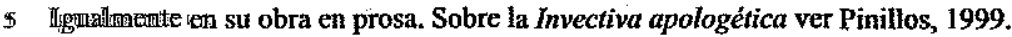

6. Gurciăh, 1981, tomo II, 197: «Es, pues la agudeza compuesta fingida un cuerpo, un todo artificioso ffingido, tque por la traslación y semejanza pinta y propone los humanos acontecimientos. Corsurpothende debajo de sí este universal género toda manera de ficciones, como san etopeyas, Imetamoríosis, alegorias, apólogos, comedias, cuentos, novelas, emblemas, jeroglíficos, empresas, ửialogos».

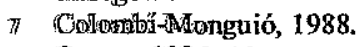

8. Campa, 1996, 44. 
co, como ya Guimbernat de González ha resaltado en varios artículos ${ }^{9}$, especialmente en el dedicado a los emblemas amorosos. Sin embargo el repertorio de motivos es tan amplio que aun pueden explorarse varios campos más: vegetales, mitología, animales, la navegación... etc. Aquí me centraré en los motivos del bestiario emblemático, comentando alguno de los principales.

En el Libro 1, el girasol se presenta mediante la metonimia mitológica, como Clicie. Aquí opera la agudeza emblemática:
Alada mayos y plumada abriles águila de las flores (bien que breve), por coronarse sol de los pensiles, muchas luces al sol Clicie le bebe. (Libro 1, XXXVIII) $^{10}$

Reina de las aves, el águila, es imagen para el girasol «Clicie» ${ }^{11}$, mediante agudeza de semejanza ya que según muestran distintos emblemas es el único animal capaz de mirar al sol sin deslumbrarse, y además símbolo de renovación al cambiar la pluma vieja mientras lo hace. Es un rasgo al que aducen emblemas como el de Borja «Vetustate relicta», Valeriano, Camerarius y otros ${ }^{12}$. En términos parecidos se ofrece la comparación del águila con el girasol «Clicie de pluma» (Libro 2, LXVII ${ }^{13}$ ), donde se superpone otra referencia emblemática: el águila que prueba sus polluelos obligándoles a mirar al sol ${ }^{14}$.

La grulla es emblema de la vigilancia, descansando sobre una sola pata mientras en la otra sostiene una piedra que deja caer al dormirse para despertar con el ruido ${ }^{15}$. Es el primer motivo emblemático de la siguiente octava:
A ti te hará esa piedra vigilante
más que a la grulla cauta piedra grave,
o escudriñe la noche instante a instante,

9 Guimbernat, 1986, 1984 y 1987.

10 Cito siempre indicando libro y estrofa, según la edición de Domínguez Camargo, 1960. Otra imagen similar en Libro 2, XCI: «Clicie, que en rudos bosqques se desata/águila de las flores, y es al prado/reloj de sus edades concertadon.

11 Para el significado emblemático del girasol, véase por ejemplo, el emblema de Sebastián Horozco de Covarrubias, «Si te vas volveréme al llanto», en Bernat y Cull, 1999, núm. 781 .

12 Borja, 1981, 12-13; Valeriano, 1556, fol. 141; Camerarius, 1604, emblema XVI del libro de las aves. Véase Henkel y Schöne, 1976, cols. 775-77.

13 Libro 2, LXVII: «distante mira al águila, que enseña/Clicie de pluma, al sol, ave obstinada/(sin que palpite el párpado), a sus hijos,/que porfien al sol los ojos fijos».

14 Es motivo central de emblemas de Remón, Sebastián de Covarrubias Horozco, Soto... reproducidos en Bernart y Cull, 1999 , núms. 37-41, 47, 50, 53...

15 Como en otras ocasiones es fácil documentar este motivo en repertorios de emblemas como los de Valeriano, Giovio, Camerarius, Nicolas Reusner, o Sebastián de Covarrubias. Ver Henkel y Schöne, 1976, cols. 820-21. 
sus párpados abriendo, atenta llave;

o ya la ancore un pie, pluma constante,

o ya navegue el aire, alada nave;

de su piedra su pluma siempre hiedra, siempre imán atractiva de su piedra.

(Libro 1, CXC)

Otros emblemas de Borja, Remón, Villava, Alciato... ${ }^{16}$ muestran este ave volando con una piedra, significando igualmente la vigilancia y la prudencia, lo que junto con la alusión a la hiedra y la piedra imán -elementos de amplio uso en la emblemática para mostrar la fijeza en la sujeción ${ }^{17}$ - aclara el resto de la estrofa.

El emblema del pelícano, ave que se rasga el pecho con el pico para alimentar o resucitar con su sangre a los polluelos, se encuentra en varios emblemistas significando la piedad en la muerte, la caridad o el valor; así en Monforte «Plangentes Adonidem suum», en Remón «Maiorem hac dilectione nemo habet, ut animam suam ponat quis, pro amicis suis» que comenta es una propiedad ya alabada por Plinio y Aristóteles, en Gómez «Pro lege et pro grege», u Ortí con el lema «Omnia vincit amor» ${ }^{18}$. Camargo se sirve de la imagen en varios lugares, con este significado convencional:

Pelicanos de España, dad la vida con la sangre al honor que mató el miedo.

(Libro 1, CXLVIII)

o la estrofa CLXI, Libro $5^{19}$ :

-Polluelos tiernos (dijo), que habéis sido implumes prendas hoy del pelicano que, a nuestro amparo el corazón rompido, su livor nos desata soberano:

Más audaz es su empleo como metáfora de la fruta granada en la descripción del banquete del bautizo del santo donde:

Pelicano de frutas, la granada, herida en sus purpúreos corazones,

16 Remón «In vigilia et pondere», Borja «Tuta merces», Villava «Nae dissipet Auster», Alciato «Quid excessi? quid admisi? quid omisi», cit. Bernart y Cull, 1999, núms. 757-48 y 760-61.

17 Bernart y Cull, 1999, núms. 1340-41 y 1410 (sobre el imán); núms. 494, 838-41 y 1194 (sobre la hiedra).

18 Bernart y Cull, 1999, núms. 287, 1292-94. Otros emblemistas (Camerarius, Junius, Vaenius...) en Henkel y Schöne, 1976, cols. 811-13.

19 Con el mismo simbolismo en Libro 4, XL: «tu boca calce al pico el pelicano/sobre el polluelo, que ensangrienta yertor. 
su leche les propina colorada, en muchos que el nubí rompió pezones. (Libro 1, LXVI)

Los versos de la octava $\mathrm{CLXXVII}^{20}$ mencionan al pavón o pavo reall y su esficta.. Es la rueda del pavo real, animal emblemático símbolo de la locura y lo vamo, segúm explica por ejemplo Núñez de Cepeda, en sus Empresas sacras, entre atros muachos repertorios (empresa 49). Comenta García Mahíques ${ }^{21}$ que el ave se convintioú en símbolo del orgullo y de la soberbia, y así aparece en Pierio Valeriano, Jam David, , etic.. El pavo al extender la espléndida rueda con sus plumas deja a la vista la fiealdigd de sens patas, denunciando su vanagloria. Muy conocido es el emblema de Peter Isseilburgs, cono el mote «Nosce te ipsum» ${ }^{22}$, o el de Villava ${ }^{23}$ con la leyenda «Deformes oblittar peafess»..

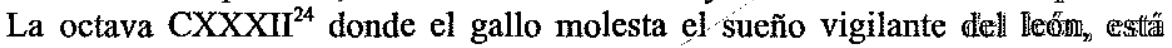
conectada con varios motivos emblemáticos. Según tradiciones zoológüicas el licón duerme vigilante con los ojos abiertos, como en el emblema de Saavedra 《Nom moajestate securus») que lo representa medio dormido ${ }^{25}$. La hipérbole camargiana por ageredęar de semejanza: «en sus ojos dos Argos aloja», enfatiza su vigilancia, com ell motivo de los cien ojos de Argos, de amplia tradición entre los emblemistas ${ }^{26}$. El león persiggaziendilo al gallo y viceversa, es emblema en varios autores: Villava con el mote «Dwm vigillom» «mientras estoy en vela ${ }^{27}$ o Lorea, «Caelisti auxilio» que comenta:

Con los alientos del sol predomina al león el gallo: pierde éste sus fuerzas cuando sale la luna, y descaece tanto de sus bríos, cuanter antes con el sol estaba alentado; por eso recobra el león, y entonces: no le teme. ${ }^{28}$

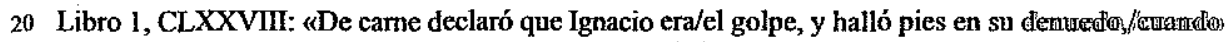

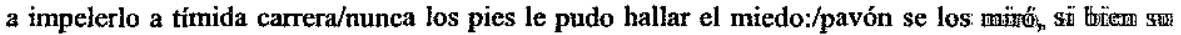
esfera/el uno repitió y el otro ruedo:/que no marchitan pompas los rubies/que blasones se eallzam carmesíes".

21 García Mahíques, 1988, 188-190.

22 Henkel y Schöne, 1976, col. 809.

23 Villava, 1613, II, empresa 27.

24 Libro 1, CXXXII: «iQué mal el gallo contra el león se arroja,/el sueño a las vigilias afternaxtoy//iii em sus ojos dos Argos éste aloja,/si canta aquel, aun cuando más se enoja,/y es bramidøe ell dé aquestle aun no enojado;/si es, el resuello de éste, al bosque espanto,/y es el grito de aquel, apenas, cantioss.

25 Saavedra, 1985, empresa 45.

26 Bemart y Cull, 1999, núms. 165 y 1278.

27 Bernart y Cull, 1999, núm. 961.

28 Bernart y Cull, 1999, núm. 955. 
Uuias @ectavas después, el león, asociado en este caso a las abejas, es una figura que se relaciona con Sansón ${ }^{29}$. El emblema se encuentra en Saavedra Fajardo («Merces

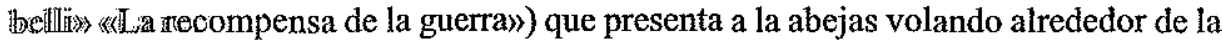
calbeza de san león muerto en el suelo. El comentario de Saavedra apura el sentido de tha ajmagen mepresentada, que se origina en el texto bíblico de Jueces, 14, 8: «En ella se dectlaria aquel enigma de Sansón del león vencido, en cuya boca, después de muerto, thacían paraalles las abejas» ${ }^{30}$.

La agudeza visual del lince es proverbial, según creencias medievales su mirada teminita el poder de horadar muros y murallas y en grabados del Renacimiento que mepresentan los cinco sentidos figura la vista representada por un lince ${ }^{31}$. Es motivo

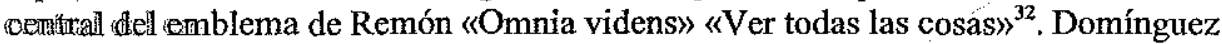
Cammange : allude a esta propiedad para construir dos imágenes del Libro segundo ${ }^{33}$. Se oppome tradicionalmente al topo ciego, que en jeroglífico de Horapollo ${ }^{34}$, es símbolo del Theranlbre ciiego, o de la ignorancia en Ripa y Camerarius ${ }^{35}$, como en la estrofa $\mathrm{X}^{36}$.

Otro gran mamífero, que tradicionalmente se encuentra en los bestiarios, es la osa llaminiendo a as cozno recién nacido para darle forma, como en los siguientes versos cannanguilamos: «de tu lengua el halago infunda humano/la osa al embrión, que informa ünciertto; ( ( $(\mathrm{L}$ ibro 4, XL), que conectan con esta tradición recogida en emblemas como loss (ae Sebasitián de Covarrubias y Horozco, o Núñez de Cepeda ${ }^{37}$ que comenta bajo el mante «Dorec formetur» «Hasta que sea formado»:

Nace el cachorro parto de la osa tan informe, y en nada parecido a su especie, que todo es una masa ruda, un bulto sin facciones, que đen si quiera menudas señas de alguna vida, hasta que el amor, artifice de raras transformaciones, hace que la madre, mirando aquel pedazo grosero de sus entrañas, se valga de la lengua como

279 Libro 11, CL: «Aquel que mura, enjambre numeroso,/la pompa flaca de su lilio de oro,/para sus Hirmibres lliba, codicioso,/el que en sus hojas derramasteis lloro;/muerto pretende a vuestro león Togoso/su oolmena el artífice canoro:/no al miedo picas haga de aguijones, /ni, corpulento, abejas en (Simsones".

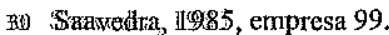

3n Ver (Chevalier y Gheerbrant, 1988, 648-49; Malaxecheverria, 1986, 18 y ss.

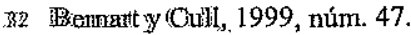

33 Lübro 2, W: «éhízose el «ah de casa» del secreto,/desterrólo a su pecho el sufrimiento;/a un lince los (dololones lle megara,/del corazón antípoda, la cara.»; LII: "Armado de un escollo en cada malla/y no

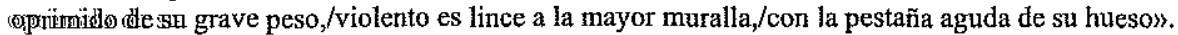

34 Ver Horapollo, 1991, 327-28 y Malaxecheverria, 1986, donde recoge textos sobre el lince y el topo (an 118-23.

ș5 Henkikel y Sơhöne, 1976, col. 490 .

376 Libro 2, X: «iVulgo de pajes se desata inquieto/y el fantástico libro solicita,el camarín divulga más secreto/y lta täás muerta alhaja resucita;/mas, al lince escrutinio, alto decreto/con ceguedad de topo lo ümittaj/y adel tiempo y del polvo relajado,/un libro sacro se encontró el cuidado».

37 Bemant y Outl, 1999, núms. 1214-15. 
instrumento, que lamiéndole le señale los ojos, le forme los oídos, le abra el olfato, le distinga los pies, y le descubra la boca.

Varios insectos pueblan el Poema heroico: se encuentra la hormiga alada, que sin alas es símbolo de orden y laboriosidad, pero cuando le nacen éstas significa la ambición, como en el emblema de Borja «In suum dispendium» «Para su daño» ${ }^{38}$, donde el emblemista comenta: «Cuando les nacen alas, es por su mayor daño, porque luego, que quieren volar, y dejar su manera de vida, se pierden $\rangle^{39}$. Con este significado se encuentra en el Libro 1, LXXXV ${ }^{40}$.

Otro insecto que encuentra su perdición en las alas es la mariposa, que atraída por el fuego, gira en torno a él hasta quemarse. Se encuentra en muchos escritores con diferentes simbolismos: es símbolo amoroso en Vaenius «Brevis et damnosa voluptas ${ }^{41}$, imagen del daño de los deseos humanos en Borja «Fugienda peto» «Busco lo que huir debría» ${ }^{42}$, engaño de las apariencias en Monforte «Mors in luce» «Muerte en la luz» $\rangle^{43}$, etc. Es un motivo emblemático al que Camargo recurre en varios lugares. Así en el canto tercero del primer Libro, el momento en que el santo cae herido en la defensa de Pamplona resistiendo las tropas francesas:

\section{Mariposa el francés, que al estandarte hispano vuela al muro, al rayo ardiente fulminado se siente de este Marte, $\mathrm{y}$ antes la muerte que la herida siente; (Libro 1, CLXIV)}

El mismo motivo emblemático funciona en otros pasajes del primer Libro (octavas CLXXIII, $\mathrm{CC}^{44}$ ), y con intertextualidad gongorina en el momento del bautizo del santo (Libro 1, XLIX) donde el verso «se temió mariposa cristalina» recuerda al v. 6 de la Soledad segunda «y su fin (cristalina mariposa)»; y en la estrofa LXXI igualmente el

38 Es también un conocido refrán que recogen Correas, 1924, 331: «Nacen alas a la hormiga para que se pierda más aína»; Rodríguez Marín, 1975, 380: «Por su mal crió alas la hormiga» y «Por su mal nacen alas a la hormiga»; Covarrubias, 1979: «hay muchas especies de hormigas y a algunas les nacen alas para perderse»).

39 Bernart y Cull, 1999, núm. 863.

40 Libro 1, LXXXV: «Donde la rueda agita de fortuna,/de la privanza licenciosa mano,/despeñando el cuerno de la luna/al que pavón sobre ella fue lozano;/ni en ocasión la clavará oportuna/el que fénix es hoy, si ayer gusano;/que a las espumas da alada fatiga/quien viste plumas de águila a la hormigà.

41 Henkel y Schöne, 1976, col. 911.

42 Borja, 1981, 66-67.

43 Bernart y Cull, 1999, núm. 1045.

44 CLXXXII: «No así, fatal, del canto breve diente,/no asi del pedernal breve gusano,/cual de la hiedra, la rüina intente/del antiguo ciprés, del roble ufano:/iOh! No siempre la llama se ensangriente; /desmiéntase una vez rayo inhumano;/no cual al junco, verde mariposa,/arda también la encina populosa»; CC: «[...] ¿Cómo repites importuno giro,/mariposa purpúrea, en luz serena,/si alado es tu período sangriento,/epitafio a tu mismo monumento?». 
«líquida mariposa desatada» remite al v. 89 de la Soledad primera: «mariposa en cenizas desatada ${ }^{45}$. En el Libro cuarto, la mariposa es figura del descarriado que se precipita en una vida de tentaciones, simbolizada en otro animal emblemático: la serpiente:

- ¿Dónde te precipitas atrevida, hidrópica de rayos mariposa, a la luz fraudulenta que a tu vida convoca dulce y matará alevosa? El lenguado fulgor que te convida con la elocuencia de su luz sabrosa, escamado de oro es un serpiente, que en la halagüeña llama esconde el diente. (Libro 4, CCXLIII)

Pocos animales hay de mayor presencia en la literatura emblemática que la serpiente, y con significados mas variados. Los vv. 3-4 de la estrofa LXXXVI (Libro 1): «donde risueña flor mulle en su seno/los áspides gitanos que alimenta» remiten al motivo virgiliano de Eurídice, mordida por la sierpe escondida en las flores ${ }^{46}$. Sierpe, es también, aunque con varias cabezas la ambición:

¡Oh ambición, que oprimida de grandezas
vistes la corte de purpúreas ropas;
sierpe, que en tantas se partió cabezas
cuantas la pretensión adoró tropas:
que brindas con hidrópicas altezas
al camaleón, que te apuró las copas,
y en ellas bebe sed el mayor Numa,
pues seca al néctar ponzoñosa espuma!
(Libro $1, X C I I)$

lo que conecta, en imagen y sentido, con el emblema de Sebastián de Covarrubias Horoz $\mathrm{co}^{47}$, donde la ambición se representa como una mujer con un vaso en la mano derecha y montada sobre un dragón de muchas cabezas, con el siguiente mote: «Qui bebit-inde, furit» «Quien allí bebe, enloquece», que remite en última instancia a la meretriz del Apocalipsis montada sobre la hidra ${ }^{48}$. Otro aspecto emblemático del áspid

46 Fam un emblema de Reusnerio reproducido en Henkel y Schöne, 1976, col. 1611.

47

48 Alciato (1985, núm. 53) representándose tradicionalmente con la boca abierta porque se mantiene del aire, y con la facultad de cambiar de color (Camerarius, Sebastián de Covarrubias en los Emblemas morales...; véase Henkel y Schöne, 1976, cols. 664-66). Los tres motivos que menciona Alciato los 
es el de la sordera al encanto. Se decía que sellaba sus oídos, aplastando uno centitial lal tierra y cerrando el otro con su propia cola. En el Poema heroico es una propiedad aludida en varias ocasiones. Así en el Libro primero, CLXXVI, es una mettáforar parat el cañón que dispara contra las murallas pamplonesas, explotando dilógicamente ell término en su acepción de «pieza de artillería de pequeño calibre»:
Áspid, con una carga el bronce duro selló el oído y su escupida esfera su tósigo fatal le flechó al muro: ¿quién, sino un áspid, tan tirano fuera?

Las conexiones emblemáticas, en este caso, serían innumerables: baste un emblexna de Camerarius, que representa con mucha exactitud al áspid en esta práctica ${ }^{49}$.. Conøetrdior es que los viboreznos al nacer despedazan el vientre de la madre; es un emablennaw repetido para la venganza en Soto, o en Villava ${ }^{50}$, y en Camargo la expresiva imaggen de un arroyo que rompe las entrañas de un monte (Libro $2, L X V^{51}$ ). Caractierístïca die: este reptil, es deshacerse de su antigua piel restregándose entre dos piedras, comø em el emblema de Sebastián de Covarrubias con el lema «Esto y más por remozame ${ }^{532}$, (1) en la hendidura de un tronco, como en Lorea «Contritione virescit» «Rejuveneee por la contrición $\rangle^{53}$. A esta muda de piel alude la estrofa CCXXVI del Libro primeres.

De todas las sierpes venenosas, culebras, áspides, etc., el basilisco es la más mortiffétra: monstruo fabuloso con alas de pájaro, cola de dragón y cabeza de gallio, prodedectio de huevo de gallo incubado por una serpiente y cuya mirada y aliento causan muertte instantánea. Se llama basilisco (de «basileus», rey), rey de las serpientes, por la cresta: que corona su cabeza. Es un motivo emblemático reiterado en toda la literattura y también en Camargo; sirvan como muestra la estrofa CLXXX del Libro primmero, ys en

cita Camargo en este y otros pasajes del Poema: Libro 3, VIIT: «No desplegandio aquíl estäi la mentira,/al ambicioso el párpado dorado,/en cuantos ojos su volumen gira;/ni en el áspidd mørdient(a) está escamado/la envidia, que sus tósigos respira/si el crecimiento ajeno ve logrado;/hii, cantral'eómi đẹll gusto de señores,/se viste la lisonja de colores»; Libro 4, XLVח: «Físico, partes; ell cønapuestio» ausculta,y aquella, que es común hospederia/de cuanta forma corporal se abulta,/materia prizmat, pe: que la varia/actïante la forma; y que resulta/en un compuesto, en que la unión l'a fia/existenter; y corrupto, aún ella existe/pues de otra forma, camaleón, se viste».

49 Está reproducido en Henkel y Schöne, 1976, col. 641, con el lema «Menten ne laedexeti autisism.

so Bernart y Cull, 1999 , núms. 1684 y 1686.

51 Libro 2, LXV: «Venera el monte, en cuya falda verde/un serpiente de espumas escanad de cristal sus giros pierde,/flexüoso entre peñas desatado,/y al risco que lo pisa, altivo muerde, /em sortijosos vínculos vibrado:/matricida cristal de dos montañas/que, al parirlo, nømquienøin suss entrañas). Bernart y Cull, 1999, núm. 515.

53 Bernart y Cull, 1999, sủm. 516.

54 Libro 1, CCXXVI: «Mudó de piel la casa, que variado/serpiente fue y vistióse las: obscupas/escamass: de bayeta, y sus enojos/desflemaron veneno por los ojos». 
el segundo la octava XCI, donde es metáfora tópica de los ojos que miran airados ${ }^{55}$. Para ejemplos de basiliscos y otras sierpes venenosas en emblemas ver Borja, Villava, Valeriano, Henkel y Schöne, o Malaxecheverría ${ }^{56}$, que señala: «Este animal representa al diablo, al mismo Satanás que se escondió en el Paraíso».

Representación del maligno es Lucifer en figura de dragón, (Libro 2, XC), iconografía habitual para el ángel caído, especialmente cuando se asocia con el arcángel San Miguel, como en los emblemas de Pérez «Origo coelistis prelium iustium» y «Qui fera sideream timerat per Ipraelia pacem ${ }^{57}$. Pero rezan los versos: «aquel que, Serafín precipitado/inflexible dragón vive la llama» aludiendo a la salamandra, pequeño dragón o lagartija, que según la tradición es el único animal capaz de sobrevivir en el fuego, como muestran numerosos emblemas (Villava, Borja, Sebastián de Covarrubias y Horozco $^{58}$, etc.). La asociación es doblemente pertinente, ya que este Serafín, tiene figura de dragón, y habita en el infierno. El áspid o serpiente es un animal asociado a varios personajes mitológicos, como Hércules niño en la cuna. Es el motivo aducido en el Libro 2, estrofa $X^{59}$, que conecta con emblemas, como los de Saavedra o Heredia ${ }^{60}$.

Varios de los animales mencionados en el Poema, están presentes pues, por su relación con fábulas mitológicas originadas en la literatura grecolatina; y de todos estos episodios de la antigüedad clásica encontramos representación en varios emblemistas. En una estrofa característica, la LXXXVI del Libro $1^{61}$, se menciona entre otros casos el del buitre que devora las entrañas de Ticio atado con cadenas, que tiene como fuente literaria a Ovidio; al igual que el emblema de Sebastián de Covarrubias Horozco con el mote «Non perit ut possit saepe perire» «No muere para que pueda morir a menudo» ${ }^{62}$, significando la eternidad de las penas. En la misma octava, se encuentra Acteón,

55 Libro 1, CLXXX: «La piedra al pie le arremetió, cobarde;/huyóle el corazón, que armó el diamante;/ratera sierpe, le pesara tarde/si al rostro un solo se atreviera instante;/pues fatal un antídoto le arde/en la vista, que luz vibra constante:/en átomos cayera sierpe flaca/que hay también basiliscos de trīaca»; ver también el texto citado en la nota anterior: Libro 1, CCXXVI; Libro 2, XCl: «Con los dos basiliscos con que mira/y con el un escuerzo en que pronuncia,de su veneno un vaho les respira,y de su pecho un trueno les anuncia:/fabricada una idea de su ira,/visible su concepto les denuncia/a aquellos que, de espíritus alados,/en dragones cayeron escamados».

56 Borja, 1981, 352; Villava, 1613, II, 47; Valeriano, 1556, fol. 105; Henkel y Schöne, 1976, cols. 627 y ss,; Malaxecheverría, 1986, 160-61.

57 Bernart y Cull, 1999, núms. 1469-70.

58 Bernart y Cull, 1999, núms. 1463-65.

59 Libro 2, XV: «Habilita la cama para cuna/del alto, si bien infante, pensamiento,/que el áspid engazado a su fortuna/ahogó en el primero movimiento:/una del lecho vivo, y otra coluna,/opuesto el uno al otro pensamiento;/y el que certamen prescribió valiente/ondas lo alternan de invisible diente».

60. Bernart y Cull, 1999, núms. 821-23.

61 Libro 1, LXXXVI: «Donde, sangriento buitre el bien ajeno,/solo un pico en cien Ticios ensangrienta;/donde risueña flor mulle en su seno/los áspides gitanos que alimenta:/donde a estragos fatiga aưn al veneno/la envidia del señor más opulenta:/y el can, que adulador, a Acteón le miente, $/ \mathrm{si}$ mudado lo ve, le imprime el diente».

62 Bernart y Cull, 1999, núm. 251 . 
que transformado en ciervo es devorado por sus propios lebrel es. Hace esta metamorfosis emblema, Alciato, moralizando contra los que se acompañan de rufianes ${ }^{63}$. A estos dos mitos de calidad emblemática aún se suma en la misma estrofa el topos de la serpiente entre flores ya comentado, en el que Camargo fusiona el motivo virgiliano, con otro emblemático, y nuevamente de origen literario clásico: «donde risueña flor mulle en su seno/los áspides gitanos que alimenta», aludiendo al emblema de la serpiente abrigada en el seno que pica a su protector, flor en este caso, cuya fuente última es una famosa fábula de Esopo ${ }^{64}$. El pasaje puede conectarse con emblemas de Sambucus y Reusnerius ${ }^{65}$ y con el emblema 14 del Libro II de los Emblemas morales de Horozco ${ }^{66}$, cuyo grabado muestra a una sierpe recogida, medio muerta de frío, por un hombre que se acerca al fuego para ser picado por la serpiente revivida al calor. La complejidad intertextual de la imagen es tal, que a los motivos emblemáticos y literarios grecolatinos, se suma la alusión gongorina a los vv. 110-11 de la Soledad I: «ni la que su alimento/el áspid es gitanos ${ }^{67}$.

Monstruo mitológico es la hidra de Lerna, que Alcides vence en uno de sus doce trabajos. En el Libro 1, CLXV ${ }^{68}$, San Ignacio es un nuevo Alcides luchando contra la hidra de tropas francesas que cercan Pamplona. Varios emblemistas, ya desde Alciato ${ }^{69}$ alegorizan los trabajos de Hércules. En Heredia ${ }^{70}$, es símbolo de la prudencia y la perseverancia, en este caso virtudes ignacianas, y de la sedición, la de los franceses. Sirve también la hidra con sus siete cabezas, de metáfora para la disciplina que se aplicaba el santo con látigo de cáñamo en la cueva de Manresa (Libro 2, CXXXIV ${ }^{71}$ ). Ya me he referido antes a la otra versión de la hidra, la apocalíptica, buena muestra de la fusión de motivos paganos y bíblicos en el trazado del poema camarguiano.

En la mitología, las sirenas aparecen como seres con cabeza y busto de mujer, y cuerpo de pez o pájaro, de canto tan atractivo que resultaba imposible resistirse a los navegantes. Diversos emblemas traen, Camerarius, Horozco Covarrubias, Saavedra Fajardo, y otros ${ }^{72}$, simbolizando la lujuria, el engaño o la hipocresía. Este es el motivo

63 Bernatt y Cull, 1999, núm. 20.

64 Esopo, 1998, 58.

65 Henkel y Schöne, 1976, cols. 637-39.

66 Bernart y Cull, 1999, núm. 512.

67 Góngora, 1994.

68 Libro 1, CLXV: «Ignacio Alcides es, clava su estoque,/si monstruosa el francés hidra lernea;/al uno y otro que fulmina toque,/una siega cerviz, otra golpea:/sin miedo, pues, que el número le apoque/(cuando ya un tronco cada cuello afea),/multitud fiera de su sangre brota, /hecha fuente de horrores cada gota».

69 Bernart y Cull, 1999, núm. 813.

70 Bernart y Cull, 1999, núm. 812.

71 Libro 2, CXXXIV: «De un tronco en ramos dividida siete,/y cada uno un escorpión de acero/si ya no sierpe, cada cual comete/a cada extremo suyo un diente fiero,/hidra rubia de cáñamo, acomete/al débil cuerpo, aun contra sí severo,/la disciplina, y escarpiar profia/sus espaldas tres veces cada día».

72 Henkel y Schöne, 1976, cols. 1697-99. 
aducido por Camargo en el Libro 4, XI, entre otros ${ }^{73}$ :

Sirenas adulaban el oído, alma canora dando al instrumento

[...]

no hay alma que no roben, entre tanto

que armoniosa es ganzúa el dulce canto.

En la tradición literaria clásica, se asocian con la figura de Ulises que en la Odisea, escapa de su seducción tapándose los oídos con cera. Es el emblema de Alciato que explica la estrofa LXXXIV, sobre la adulación:

Donde la adulación, siempre sirena, propinando está tósigo armonioso, en el que dulcemente labio suena

[...], y solo aquel se salva, en su carrera, que antídoto al oído da de cera.

(Libro 1, LXXXIV)

En conclusión, la presencia de lugares emblemáticos (y sólo hemos señalado algunos ${ }^{74}$, relativos al bestiario) en la obra, es realmente importante y muchas octavas se estructuran en su totalidad en torno a la acumulación ingeniosa de meras relaciones microtextuales de motivos emblemáticos (recuérdese la estrofa LXXXVI del Libro 1).

Sin embargo, aunque abundante la presencia de animales en el Poema, no es muy variado el universo de los representados, que el poeta repite constantemente. No se trata de un especial aprecio a unos emblemas concretos, no muestra una preferencia especial por un autor, o un libro de emblemas, es decir no podemos señalar fuentes concretas, que por otra parte serían comunes a los otros ingenios de la época, como Cervantes,

73 Libro 1, CLIII: «Si rémora es su aliento a su carrera,/áncora firme a fugitivas naves,/Sirena atrae después (bien que severa)/los ánimos con vínculos süaves».

74 En el reducido espacio de esta comunicación no puedo comentar y documentar otros como el rinoceronte (Libro 2, LII) que no se sujeta a ningún peso significando la resistencia al yugo o servidumbre de los vicios (Borja, 1981, 234-35); el dulce canto del cisne antes de morir (Libro 3, XI), motivo tradicional, y como tal recogido en emblemas como el de Remón, (Bernart y Cull, 1999, núm. 390.); la rémora, animal marino que es impedimento mental al alma (Libro 2, V) en consonancia con el significado đel emblema de Alciato «Contra los que fácilmente se apartan de la virtud» (Bernart y Cull, 1999, núm. 1143), o el de Borja que discurre en términos semejantes, con idéntica imagen de una nave con las velas despegadas, sin moverse en el agua -camino de virtud--, a causa de la rémora; y por supuesto, el ave fénix (Libro 4, XL; Libro 5, XXXVI), animal mitológico omnipresente en toda la literatura y no sólo la áurea. Sobre este animal fantástico y su resurrección de las cenizas en que él mismo se quema, los testimonios son innumerables, desde Plinio, Ovidio y otros autores clásicos hasta Sebastián de Covarrubias. Traen emblemas Camerarius, Valeriano, Horapolo... (ver Henkel y Schöne, 1976, cols. 795-96). 
Calderón, etc. La acumulación y la inserción en esquemas de la agudeza culta, y el valor nuclear que se confiere a estos elementos, demuestran, sin embargo, que, sean o no sean mostrencos, estos materiales constituyen un componente esencial del complejo, y suntuoso edificio poético de Hernando Domínguez Camargo.

\section{Bibliografía}

Alciato, Emblemas, ed. de S. Sebastián, Madrid, Akal, 1985.

Arellano, I., «Piedras y pájaros: ilustración extravágante a un pasaje del Médico de su honra de Calderón», Bulletin Hispanique, Homenaje a M. Chevalier, 92, 1990, núm. 1, 59-69.

- «Motivos emblemáticos en el teatro de Cervantes», BRAE, LXXVII, 1997, 419-43.

- "Visiones y símbolos emblemáticos en la poesía de Cervantes», Anales cervantinos, 34, 1998, 169-212.

— «Emblemas en el Quijote», en La emblemática en el Siglo de Oro. Coloquio del GRISO, Pamplona, 1999, Universidad de Navarra, actas en prensa.

Bernart Vistarini, A. y J. T. Cull, Enciclopedia de emblemas ilustrados, Madrid, Akal, 1999.

Borja, J. de, Empresas morales, ed. facsímil de C. Bravo Villasante, Madrid, FUE, 1981 , que reproduce la de 1680 preparada, con añadidos, por Francisco de Borja, nieto del autor, el cual la había sacado en primera edición en 1581.

Camerarius, J., Symbolorum et emblematum ex aquatilibus et reptilibus, 1604. Ver Henkel y Schöne, 1976.

Campa, P. F., «La génesis del libro de emblemas jesuita», en Literatura emblemática hispánica, I simposio internacional, Universidad de la Coruña, 1996, 43-60.

Chevalier, J. y A. Gheerbrant, Diccionario de los símbolos, versión castellana de M. Silvar y A. Rodríguez, Barcelona, Herder, 1988.

Colombí-Monguió, A., «Verba significans, res significantur: libros de empresas en el Perú virreinal», NRFH, XXXVI, 1988, 345-64.

Correas, G., Vocabulario de refranes y frases proverbiales, Madrid, RAE, 1924.

Covarrubias, S. de, Tesoro de la lengua castellana, Madrid, Turner, 1979.

Cull, J., «Death as Great Equalizer in Emblems and in Don Quijote», Hispania, 75, 1992a, 8-17.

- «Emblematics in Calderón's El médico de su honra», Bulletin of the comediantes, 44, 1, 1992b, 113-31.

Domínguez Camargo, H., Obras, ed. a cargo de R. Torres Quintero, con estudios de A. Méndez Plancarte, J. A. Peñalosa y G. Hernández de Alba, Bogotá, Caro y Cuervo, 1960. 
Esopo, Fábulas, Madrid, Alianza, 1998.

García Mahíques, R., Empresas sacras de Núñez de Cepeda, Madrid, Tuero, 1988.

Gracián, B., Agudeza y arte de ingenio, ed. de E. Correa Calderón, Madrid, Castalia, 1981,2 vols.

Góngora, L. de, Soledades, ed. de R. Jammes, Madrid, Castalia, 1994.

Guimbernat, A., «La poesía emblemática de Hernando Domínguez Camargo», en Actas del VIII Congreso de la AIH, I, ed. de A. D. Kossoff et. al., Madrid, Istmo, 1986, 61521.

- «El nieto ciego de la blanca espuma»: Ios emblemas de amor en el Poema heroico de Hernando Domínguez Camargo», Revista de Estudios Hispánicos (Puerto Rico), 11, 1984, 153-62.

- «Apeles de la reínscripción: a propósito del Poema heroico de Herando Domínguez Camargo», Revista Iberoamericana, 53, 1987, 569-79.

Henkel, A. y A. Schöne, Emblemata, Stuttgart, 1976.

Horapollo, Hieroglyphica, ed. de J. M. González de Zárate, Madrid, Akal, 1991.

Iffland, J., «Don Quijote como Sileno: ¿Una pista para descifrar las intenciones de Cervantes?», Anales cervantinos, 34, 1998, 135-44.

Malaxecheverría, I., Bestiario medieval, Siruela, Madrid, 1986.

Núñez de Cepeda, ver García Mahiques.

Pinillos, M. C., «Emblemas en el Quijote. El episodio de las bodas de Camacho», Criticón, 71, 1997, 93-103.

- «La Invectiva apologética de Hernando Domínguez Camargo. Notas para su edición», en Edición y anotación de textos coloniales hispanoamericanos, ed. de I. Arellano y J. A. Rodríguez Garrido, Biblioteca Áurea Hispánica, 6, Iberoamericana, Vervuert, 1999, 285-303.

Praz, M., Studies in Seventeenth Century Imagery, Roma, Edizioni di Storia e Letteratura, 1964.

Rodríguez Marín, F., Más de 21000 refranes..., Madrid, Atlas, 1975.

Saavedra Fajardo, D., Empresas políticas, ed. facsímil de Murcia, Universidad, 1985. Smith, D. L., "Tirso"s Use of Emblems as a Technique of Representation in La mujer que manda en casa», Bulletin of the Comediantes, 37, 1, 1985, 71-81.

Valeriano, P., Hieroglyphica, Basileae, 1556.

Villava, F. de, Empresas espirituales y morales, Baeza, 1613. 